\title{
Comparison of continuous local anaesthetic and systemic pain treatment after axillary lymphadenectomy in breast carcinoma patients - a prospective randomized study
}

\author{
Branka Strazisar ${ }^{1}$, Nikola Besic ${ }^{2}$ \\ ${ }^{1}$ Department of Anaesthesiology and ${ }^{2}$ Department of Surgical Oncology, Institute of Oncology, Ljubljana, Ljubljana, Slovenia
}

Radiol Oncol 2013; 47(2): 145-153.

Received 8 December 2012

Accepted 22 December 2012

Correspondence to: Nikola Besic, MD, PhD, Department of Surgical Oncology, Institute of Oncology, Zaloska 2, 1000 Ljubljana, Slovenia. Phone: +386 15879 953; Fax: +386 15879 400; E-Mail: nbesic@onko-i.si

Disclosure: No potential conflicts of interest were disclosed.

\begin{abstract}
Background. Acute pain after axillary lymphadenectomy is often related mainly to axillary surgery. The aim of the prospective randomized study was to find out if continuous wound infusion of local anaesthetic reduces postoperative pain, consumption of opioids and the incidence of chronic pain compared to the standard intravenous piritramide analgesia after axillary lymphadenectomy in breast carcinoma patients.

Methods. Altogether 60 patients were enrolled in the prospective randomized study; half in wound infusion of local anaesthetic and half in the standard (piritramide) group.

Results. In the recovery room and on the first day after surgical procedure, the wound infusion of local anaesthetic group reported less acute and chronic pain, a lower consumption of piritramide and metoclopramide, but their alertness after the surgical procedure was higher compared to the standard group.

Conclusions. After axillary lymphadenectomy in breast carcinoma patients, wound infusion of local anaesthetic reduces acute pain and enables reduced opioid consumption, resulting in less postoperative sedation and a reduced need for antiemetic drugs. After wound infusion of local anaesthetic there is a statistical trend for reduction of chronic pain.
\end{abstract}

Key words: breast carcinoma; pain treatment; wound infusion of local anaesthetic; elastomeric pump

\section{Introduction}

The sense of pain is an individual experience; it depends on pain memories and present circumstances. ${ }^{1}$ Breast cancer surgery can be painful, but acute pain is often related mainly to axillary surgery. Furthermore, breast surgery can be emotionally distressing. ${ }^{2}$ The risk of clinically meaningful acute pain was increased in patients with preoperative anxiety. ${ }^{3}$ Surgery and inflammation that follow the intervention, activate peripheral nociceptors in the skin, ligaments and muscles. A noxious stimulus is propagated by thin, unmyelinated $C$ type fibres and thinly myelinated A-delta fibres to the central nervous system. ${ }^{4}$ During axillary lymph node dissection, the surgeon should avoid an injury of the long thoracic and thoracodorsal nerve, because the lesion of these nerves causes a muscular deficit and results in physical deformities. ${ }^{5}$ However, the intercostobrachial nerves are often injured or cut during axillary surgery. Already a small lesion of these nerves can cause pain. ${ }^{6}$ Despite a meticulous surgical technique; there is a $35 \%-50 \%$ risk of developing numbness, pain, or paraesthesia.

Patients who develop pain or paraesthesia are at risk of progression to chronic pain syndromes. Five years after axillary dissection, as many as 30\% of patients continue to experience symptoms. ${ }^{7,8}$ 
Chronic pain syndrome after axillary dissection for breast carcinoma is known as post-mastectomy syndrome. ${ }^{9}$ The chronic pain syndrome is often a result of inadequately treated acute pain. ${ }^{10}$ Persistent pain can be avoided through continuous use of a sufficient level of pain medication. ${ }^{9}$ Perioperative analgesia has traditionally been provided by opioid analgesics. Large doses of opioids can be associated with an increased incidence of postoperative complications: respiratory depression, sedation, nausea and vomiting, pruritus and ileus. ${ }^{11,12}$ Therefore, anaesthesiologists and surgeons are increasingly turning to non-opioid analgesic techniques for managing pain during the perioperative period in order to minimize the adverse effects of analgesic medications. ${ }^{12}$ Local anaesthetics can improve postoperative pain management. ${ }^{11}$ They suppress the afferent nociceptive signal and inflammatory reaction. ${ }^{13}$ Local anaesthetics for postoperative analgesia are used in many fields of surgery: orthopaedics, abdominal surgery, gynaecology, urology, cardiothoracic surgery and breast cancer surgery. ${ }^{14}$ Continuous administration of local anaesthetics into the wound via a catheter placed directly at the end of surgery represents a simple and efficacious means to provide postoperative analgesia. ${ }^{15,16}$ At the Institute of Oncology in Ljubljana, intravenous administration of the opioid piritramide is a standard treatment of perioperative pain. Piritramide is used because it has lower frequency of side effects, i.e. vomiting, respiratory depression or cardiovascular instability, compared to morphine. ${ }^{17}$ Based on good results of our retrospective data; we wanted to prove the superiority of the continuous local anaesthetic infusion over the standard intravenous analgesia after axillary dissection in breast cancer patients. We hypothesized that a continuous infusion of the local anaesthetic through a wound catheter after axillary dissection in breast carcinoma patients reduces acute pain more effectively than the standard intravenous opioid analgesia. Our prospective randomized study was also aimed at testing if the patients with a continuous infusion of the local anaesthetic have a lower consumption of opioids, a lower need for antiemetic drugs, lower sedation, and less frequent chronic pain compared to the standard opioid based analgesia group of patients.

\section{Patients and methods}

\section{Methods}

Patients listed for axillary dissection because of breast cancer were screened preoperatively dur- ing the routine anaesthetic assessment. Allergies to local anaesthesia, male gender or dependence on analgesics were the criteria excluding patients from our study. Female patients undergoing breast cancer surgery with axillary dissection were randomized into a group having a wound catheter with elastomeric pump, or into the standard piritramide treatment group. From December 2010 to July 2011, a total of 60 patients were enrolled: 30 patients in the test group and 30 in the standard group.

The study was reviewed by the appropriate Ethics Committee and performed in accordance with the ethical standards laid down in an appropriate version of the 1964 Declaration of Helsinki. Our study was approved by the Institutional Review Board and conducted with the understanding and consent of the involved human subjects.

The surgical procedure was performed during general anaesthesia. Anaesthetic technique for all the patients was the same. All of them received a single prophylactic dose of antibiotic before the beginning of the surgical procedure. Patients without diabetes received $4 \mathrm{mg}$ of dexamethasone. All patients were given $1 \mathrm{mg}$ of granisetron in order to prevent nausea. Before the end of the surgical procedure, all patients received our standard analgesic infusion mixture, which contained $7.5 \mathrm{mg}$ of piritramide, $2.5 \mathrm{~g}$ metamizole and $10 \mathrm{~g}$ of metoclopramide.

\section{Test group of patients}

Before wound closure, 30 patients, who were randomized into the test group, received a fenestrated wound catheter, which was placed into their wound cavity near to the axillary vein and upon the whole length over the upper side of the wound. The wound catheter was fenestrated in the distal part, $15 \mathrm{~cm}$ in length. A bolus of $15 \mathrm{ml}$ of $0.25 \%$ levobupivacaine was injected in the wound through the catheter immediately after wound closure. Soon after the administration of bolus, the elastomeric pump was connected to the wound catheter.

Surgical drains and the fenestrated catheter were clamped for five minutes after the administration of levo-bupivacaine in order to enable the absorption of levo-bupivacaine from the bolus. After five minutes, clamps on surgical drains were released in order to evacuate seroma. After another 15 minutes, the clamp on fenestrated catheter was also released, enabling a continuous infusion of levo-bupivacaine. The amount of the local anaesthetic in the elastomeric pump was $100 \mathrm{~mL}$ at the 
TABLE 1. Characteristics of patients

\begin{tabular}{|c|c|c|c|c|}
\hline Number of patients & & 30 & 30 & - \\
\hline Age (years) - mean & & 57.4 & 62.9 & 0.79 \\
\hline Height (m) - mean & & 1.62 & 1.637 & 0.43 \\
\hline Weight (kg) - mean & & 72.7 & 73.8 & 0.76 \\
\hline Associated diseases & & 19 & 24 & 0.25 \\
\hline Diabetes mellitus & & 4 & 8 & 0.33 \\
\hline Fibromyalgia & & 0 & 1 & - \\
\hline Type of invasive carcinoma & $\begin{array}{l}\text { Ductal } \\
\text { Lobular }\end{array}$ & $\begin{array}{c}28 \\
2\end{array}$ & $\begin{array}{c}27 \\
3\end{array}$ & 1.00 \\
\hline Gradus & $\begin{array}{l}\text { I } \\
\text { II } \\
\text { III }\end{array}$ & $\begin{array}{c}0 \\
11 \\
19\end{array}$ & $\begin{array}{c}1 \\
11 \\
18\end{array}$ & 1.00 \\
\hline Metastatic lymph nodes - mean & & 5.2 & 5.3 & 0.37 \\
\hline Resected lymph nodes - mean & & 17.3 & 19.3 & 0.15 \\
\hline Hormone receptors positive & & 24 & 26 & 0.73 \\
\hline HER-2 positive & & 5 & 6 & 1.00 \\
\hline
\end{tabular}

flow rate of $2 \mathrm{~mL}$ per hour. The catheter was removed 50 hours later, when the elastomeric pump reservoir was empty.

\section{Control group of patients}

The control patients, i.e. those who received the standard intravenous piritramide treatment, were on a continuous intravenous infusion with piritramide $(30 \mathrm{mg})$, metoclopramide $(20 \mathrm{mg})$ and metamizole $(2.5 \mathrm{~g})$ in total amount of $100 \mathrm{~mL}$ of saline until the next morning. The rate of infusion was between $3 \mathrm{~mL} / \mathrm{h}$ and $6 \mathrm{~mL} / \mathrm{h}$. The nursing staffs were instructed to maintain the lowest rate of drip infusion, which relieved the patient of her pain. The volume of infusion has been registered.

Both groups of patients could get the intravenous bolus of a rescue analgesic or an antiemetic drug whenever needed. In a case of severe pain, the patient received a bolus of $3 \mathrm{mg}$ of piritramide. A total consumption of all intravenous drugs used during the first 24 hours after the surgical procedure was registered.

\section{Pain measurement}

Pain was measured using a standard visual analogue scale (VAS) score in ranging from 0 to 10 . The first measurement was made in the recovery room. Thereafter, pain was measured three, six and nine hours after the surgical procedure. Over the next two days, pain was measured every eight hours. Six hours after the surgical procedure, we measured their alertness using the Observer's Assessment of Alertness/Sedation Scale (OAA/S Scale) in a composite way. ${ }^{18}$ The OAA/S Scale score is composed of four categories: 1) responsiveness, 2) speech, 3) facial expression, and 4) eyes. The composite score ranges from 1 (deep sleep) to 5 (alert). The result is the lowest level observed by the nurse in any one of the four component scores.

In case of nausea or vomiting, the patient received a bolus of an antiemetic drug, the first one being metoclopramide. If no relief was achieved, $1 \mathrm{mg}$ of granisetron or, with persistent nausea, $1.25 \mathrm{mg}$ of droperidol was administered intravenously. On the first postoperative day, all patients 
TABLE 2. Treatment of patients and chronic pain after adjuvant therapy

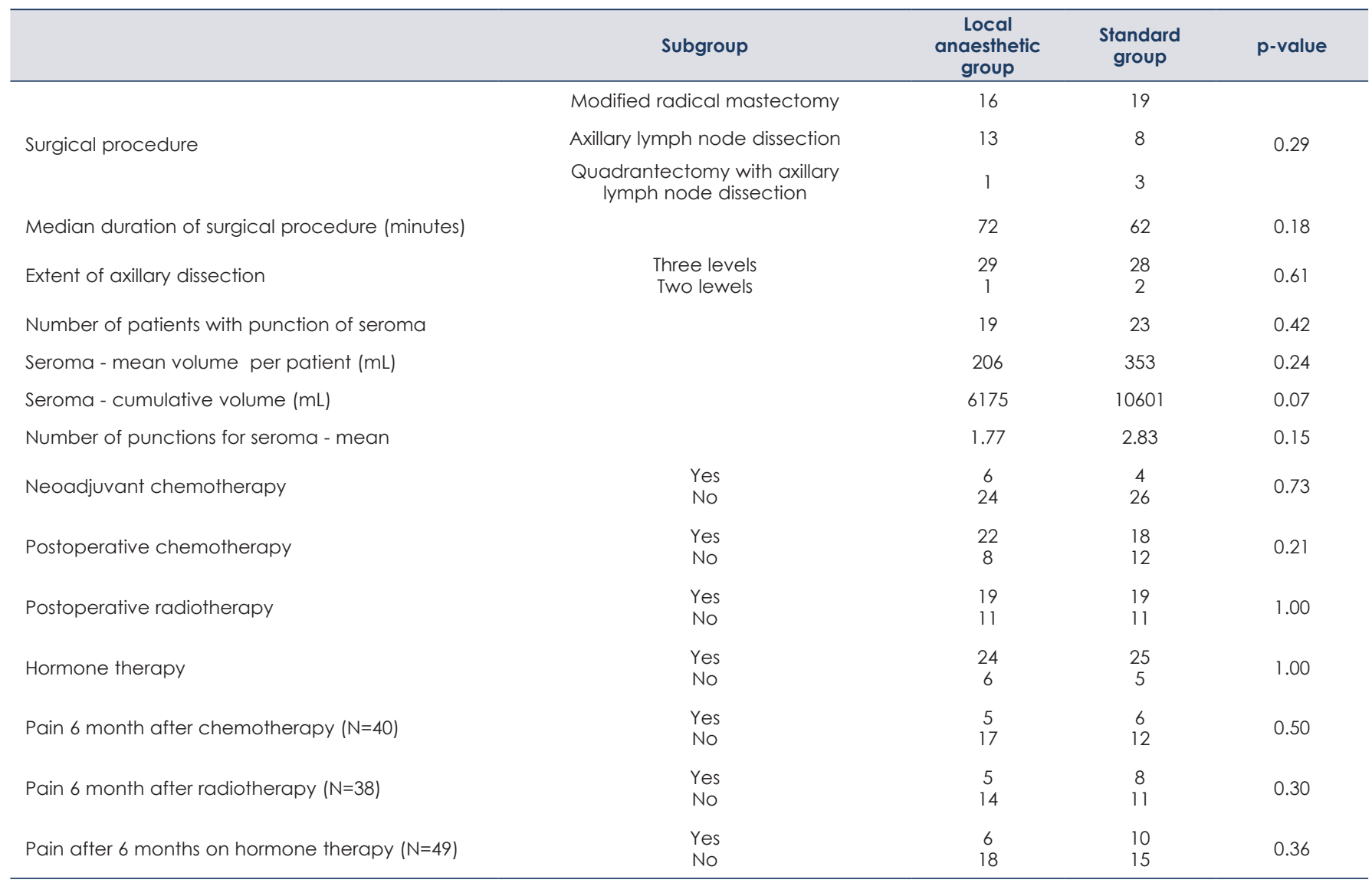

received analgesics in the form of tablets. They were administered $100 \mathrm{mg}$ of diclofenac, a combination of paracetamol and tramadol and, in case of nausea, an antiemetic drug. The consumption of drugs during hospitalization was registered.

After surgical procedure the majority of patients had adjuvant treatment: chemotherapy $(67 \%)$, irradiation (63\%) and/or hormone therapy (82\%).

All complications (inflammation, hematoma and others) were recorded. Three months after the surgical procedure the patients were asked about pain in the postoperative area or the upper extremities. All patients were examined and asked about neuropathic pain in the axilla, shoulder, arm or chest wall six months after the surgical procedure.

\section{Statistical analysis}

The student t-test or the Mann-Whitney $U$ test was conducted according to the data distribution. The association between categorical variables was tested by chi $^{2}$ or Fisher's exact test, as appropriate. All comparisons were two-sided and a p-value of $\leq 0.05$ was considered statistically significant. Statistical packages PASW 18 (SPSS Inc., Chicago, IL, USA) and R 2.11.1 (R Foundation for Statistical Computing, Vienna, Austria) were used for the analysis.

\section{Results}

The mean age of patients was 60 years (range 3084), height $163 \mathrm{~cm}$ (range 150-176), weight $73 \mathrm{~kg}$ (range 43-114), and body mass index (BMI) 27.4 (range 15.4-41.4). There were no significant differences between both study groups either in BMI, American Society of Anaesthesiology (ASA) score, comorbidities (Table 1), length of surgical procedure, extent of lymph node dissection, volume of seroma or number of punctions of seroma (Table 2).

All lymphadenectomies were performed by eleven experienced surgeons. There were no significant differences between various surgeons either in VAS score during hospital stay $(\mathrm{p}=0.66)$ or in rate of chronic pain after six months $(\mathrm{p}=0.32)$. 

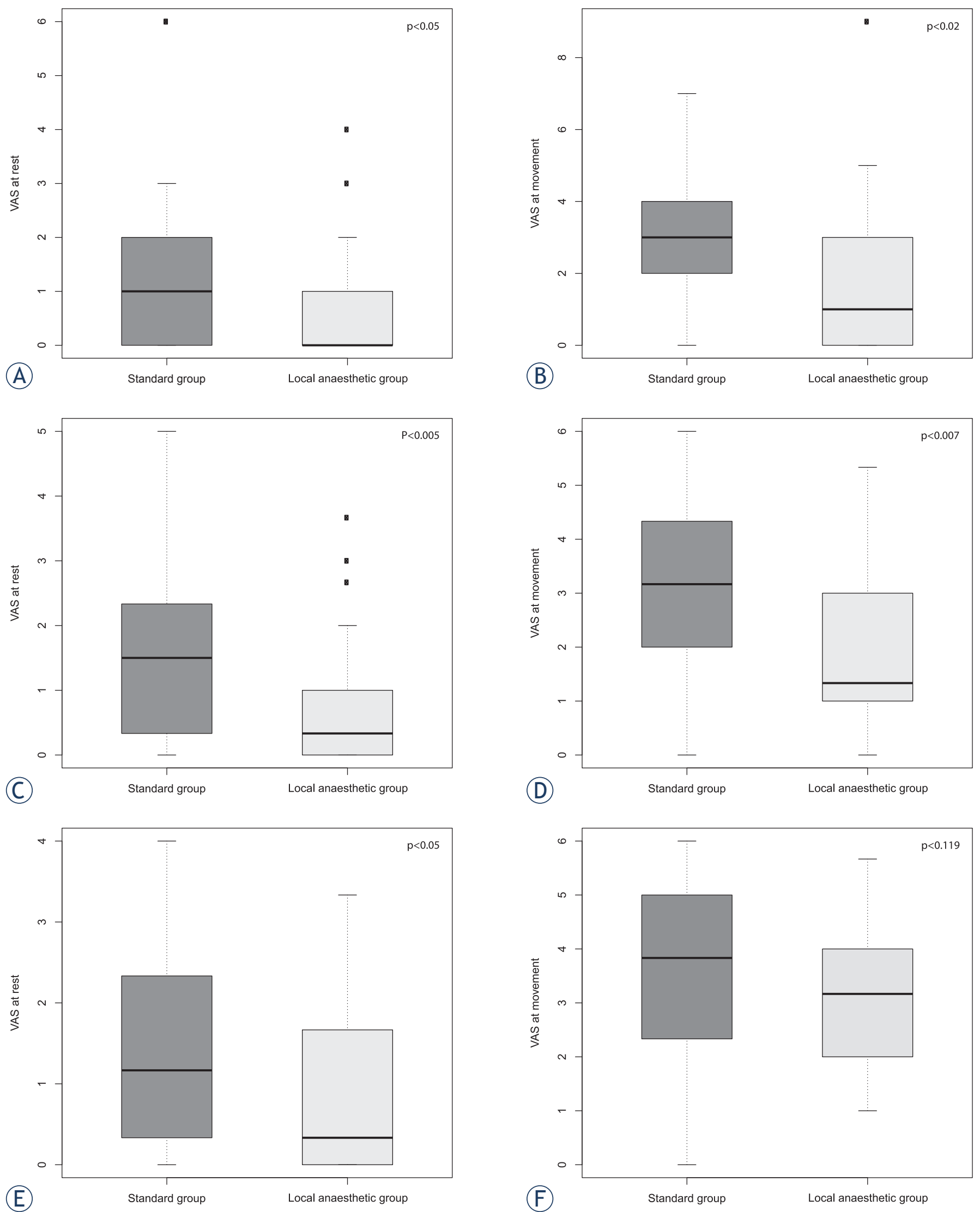

FIGURE 1. Visual analogue scale (VAS) scores at rest and at movement in the recovery room (A, B) on the day of the surgery (C, D) on the first postoperative day (E, F). 
TABLE 3. Pain, consumption of drugs and alertness in local anaesthetic group and standard group of patients

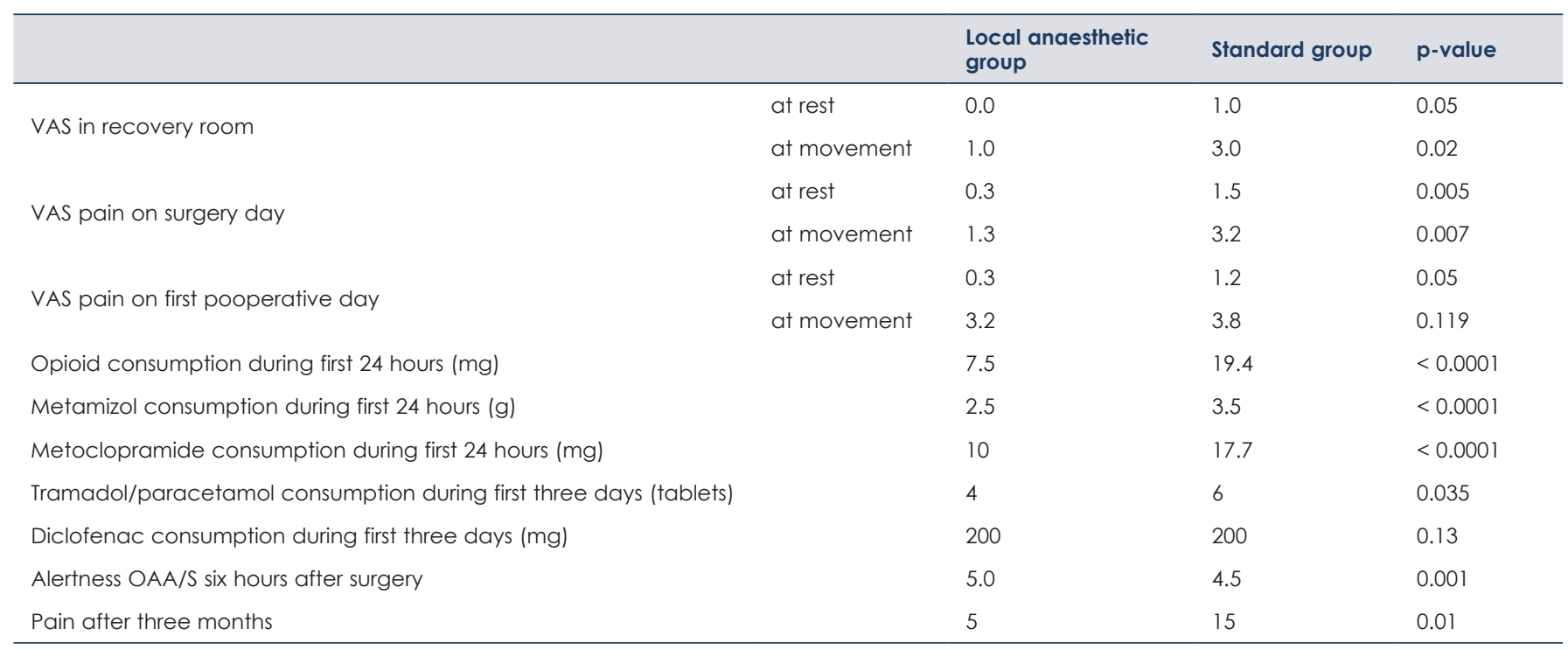

Data is presented as the median value or number.

$\mathrm{VAS}=$ visual analogue scale; OAA/S = Observer's Assessment of Alertness/Sedation

\section{Acute pain}

Figure 1 shows VAS scores at rest and during movement in the recovery room on the day of the surgery and on the first postoperative day. Data about postoperative pain in VAS scores are presented in Table 3.

\section{Opioid consumption}

Consumption of piritramide during the first 24 hours after the surgical procedure was smaller in the test group compared to the control group $(\mathrm{p}<$ 0.0001) (Figure 2). Alertness, as measured six hours after the surgical procedure, was higher in the test group compared to the test group $(p=0.001)$.

\section{Nausea}

Patients in the test group reported less nausea than patients in the standard group. Consumption of metoclopramide during the first 24 hours (Figure 3 ) after the surgical procedure was also smaller in the test group compared to the standard group ( $\mathrm{p}<$ 0.0001).

\section{Complications}

No local signs of infection were observed in the area, where the wound catheter was inserted. All microbiological samples taken were negative. There were no significant differences in the complications following the surgical procedure between the two groups. Altogether three patients (5\%) underwent another surgical procedure because of haematoma: two cases from the test group and one case from the standard group. Inflammation after the surgical procedure occurred in nine cases (15\%): five cases $(17 \%)$ in the test group and four cases $(13 \%)$ in the standard group.

\section{Hospital stay}

The average postoperative hospital stay was 1.7 days. There was no significant difference in the duration of the hospital stay between the two groups.

\section{Late complications (three and six months after lymphadenectomy)}

Questionnaire about pain was answered by patients three months after lymphadenectomy. Pain was reported by $17 \%$ and $50 \%$ of patients from test and control group ( $p=0.01)$, respectively. Six months after surgical procedure patients from test and control group had neuropathic chronic pain in $20 \%$ and $40 \%(p=0.09)$, respectively. Oedema of the arm was present in 21 patients, 10 from the control group and in 11 from the test group. Limited shoulder movement was present in 14 patients $(23.3 \%), 7$ from each group. Chronic pain after 6 month was present in 18 patients (30\%). There 
were no differences in both arms of our study in frequency of chronic pain after adjuvant treatment (Table 2).

\section{Discussion}

Axillary lymph node dissection is a standard surgical procedure in case of positive lymph nodes in breast cancer or melanoma. ${ }^{19-21}$ Unfortunately, it can cause long-term morbidities: chronic postoperative pain, limited shoulder movement and/ or lymphoedema. ${ }^{5,6}$ Our present prospective randomized study showed that acute pain following breast cancer surgery and axillary lymph node dissection was less frequent and intense after a continuous wound infusion of local anaesthetic compared to a systemic intravenous analgesia with opioids. To our knowledge, there were only six studies dealing with the use of a local anaesthetic for postoperative analgesia in breast carcinoma patients. ${ }^{2,5,9,13,22,23}$ In only three of these studies $^{2,5,9}$, a local anaesthetic was applied to the surgical wound, and only two ${ }^{2,5}$ of these three studies were designed as a prospective randomized trial. Jacobs and Morrison reported the results of a retrospective study, where the wound catheter was connected to an elastomeric pump containing local anesthetic. ${ }^{9}$ They found out that this type of analgesia was safe and reduced postoperative pain. ${ }^{9}$ Talbot et al. performed a prospective, double-blind, randomized, placebo controlled trial on 42 patients after a modified radical mastectomy. ${ }^{2}$ They did not find any difference in analgesia between the treatment group, which received levo-bupivacaine irrigation through the axillary wound drain every four hours for the first 24 hours postoperatively, and the control group, which received irrigation with normal saline. ${ }^{2}$ Instead of perforated catheters, they used axillary drains, which were clamped for 20 minutes every four hours following the application. Thus, a local anaesthetic was not administered continuously. Furthermore, because they did not use perforated catheters, it is questionable if the local anaesthetic irrigated the entire wound area. Our patients with a continuous infusion of local anaesthetic had a lower consumption of opioids and a reduced need for antiemetic drugs compared to the standard opioid-based analgesia group of patients. These results are in accordance with the conclusions of the majority of investigators who studied the role of local anaesthetics in postoperative pain management. 5,9,13,23-29

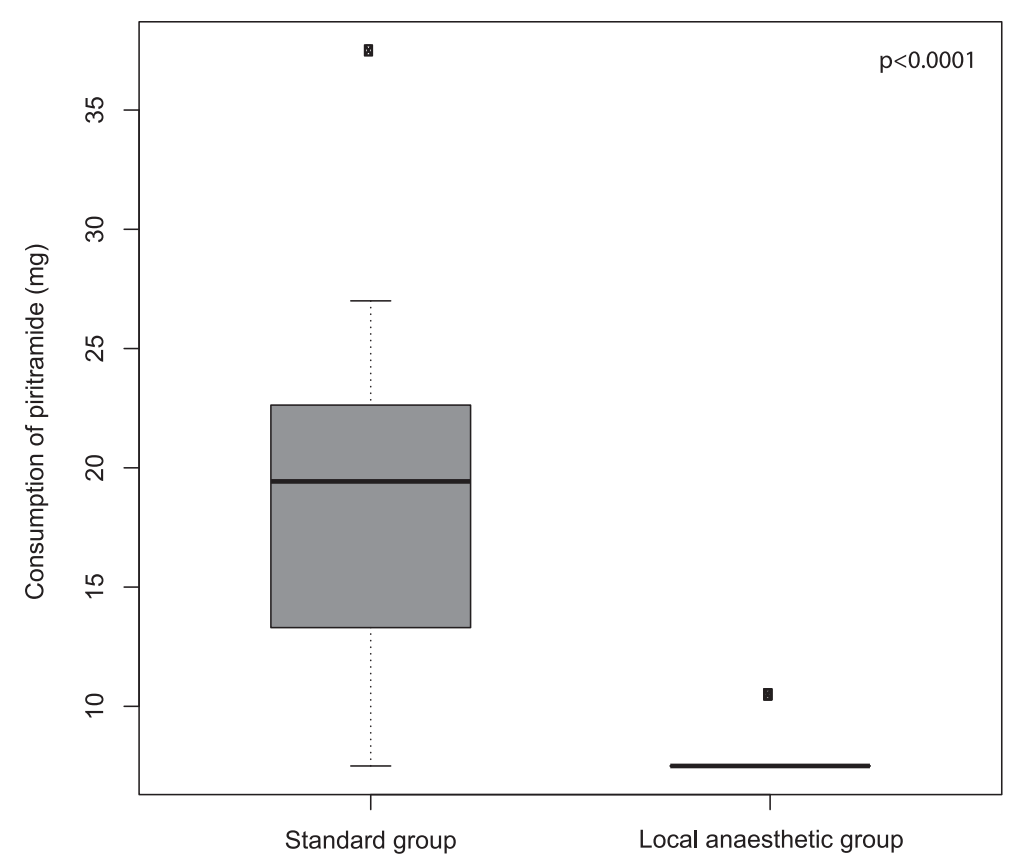

FIGURE 2. Consumption of piritramide during the first 24 hours after the surgical procedure in the local anaesthetic group and in the standard group.

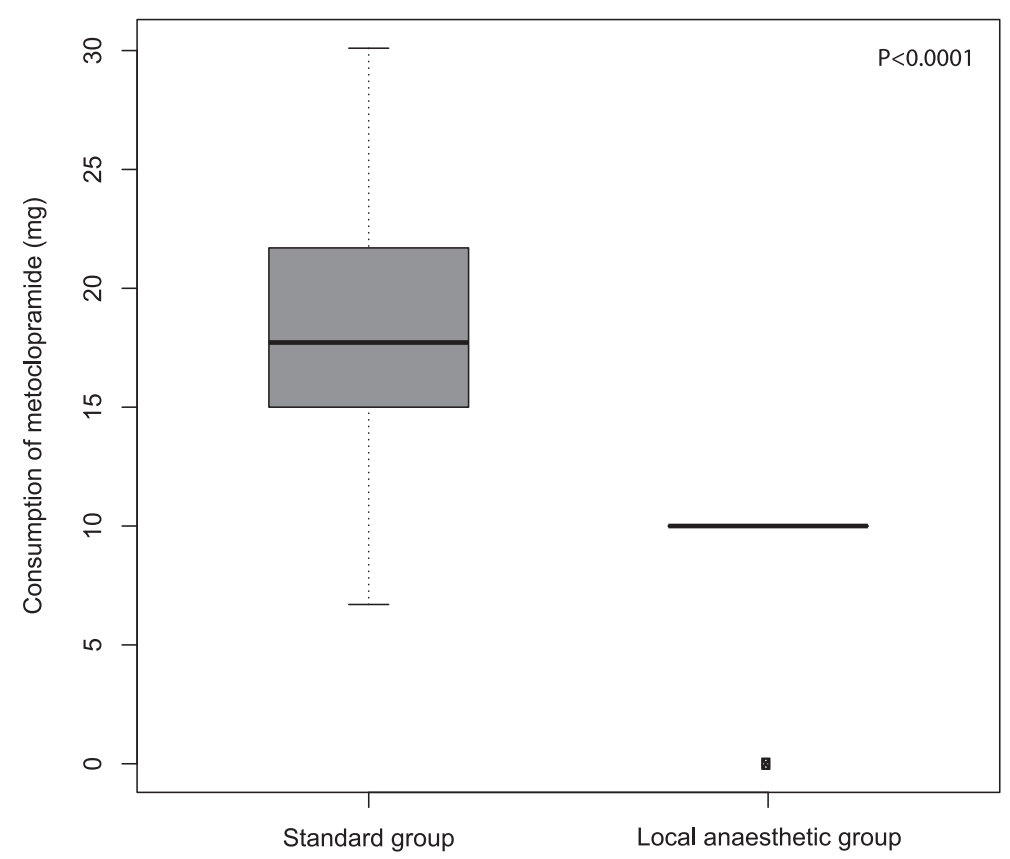

FIGURE 3. Consumption of metoclopramide during the first 24 after the surgical procedure in the local anaesthetic group and in the standard group.

In our study a cost-benefit analysis was not done. The costs of drugs were almost the same in both study arms. So, the cost of treatment with elastomeric pain pump is bigger than standard pain treatment for a price of elastomeric pain pump and perforated catheter, which is 175 Euros 
in our country. But, we proved that patients with a continuous infusion of local anaesthetic had a lower sedation rate compared to the standard opioid-based analgesia group of patients as a consequence of a reduced use of opioids. Almost all patients from the test group had an excellent alertness OAA/S score already on the day of the surgical procedure. Therefore, we believe that a continuous infusion of a local anaesthetic represents a very good pain management option for patients who underwent axillary lymph node dissection and are thus treated as a day case, which has already become a standard of care in some hospitals, for example in the Memorial Sloan-Kettering Cancer Centre in New York. ${ }^{30}$ Painless postoperative patient management and a shorter hospital stay are an essential part of a patient-friendly treatment.

Another very important issue of breast cancer treatment after axillary surgery is the incidence of chronic pain. Many factors are involved in the development of chronic pain after a surgical procedure: genetic susceptibility, psycho-social background, age and gender. ${ }^{31}$ Smith et al. identified age, marital status, employment status and housing as risk factors for post-mastectomy pain syndrome. ${ }^{32}$ Many studies and reviews have noted that a more severe acute postoperative pain is a risk factor for the development of chronic postoperative pain. ${ }^{16}$ It is well known that an infusion of local anaesthetics in the peripheral nerve sheath reduces the incidence of chronic pain after a lower limb amputation ${ }^{33}$, and that an epidural block with a local anaesthetic before the surgery reduces longterm post-thoracotomy pain. ${ }^{34}$ However, the use of a local anaesthetic immediately after the surgical procedure to prevent the post-mastectomy pain syndrome is still not sufficiently defined. Three months after lymphadenectomy, our patients on postoperative continuous infusion of local anaesthetic reported pain less often than patients on opioid-based analgesia ( $17 \%$ vs. $50 \%$; p $=0.01)$.

However, six months after lymphadenectomy there was just a trend for lower pain in continuous infusion of local anaesthetic group of patients in comparison to opioid-based analgesia (20\% vs. $40 \%$; $p=0.09$ ). Similar outcome on occurrence of post-mastectomy pain syndrome was reported by Fassoulaki et al. ${ }^{13,22}$ In their first study, the anaesthetic cream was applied locally on the skin just before and at the end of the surgical procedure, and daily thereafter for a total of four days. The incidence of pain three months after surgical procedure was $43 \%$ in the study group and $91 \%$ in the placebo group $(p=0.002) .{ }^{22}$ In their second study, the incidence of pain after three months was $45 \%$ in the treatment group (local anaesthetic cream, irrigation of brachial plexus and intercostal places with a local anaesthetic and gabapentin tablets) versus $82 \%$ in the placebo group $(\mathrm{p}=0.028)$. They reported that chronic pain after six months in the treatment group $(30 \%)$ was less common than in the placebo group (57\%), but the difference was not significant. Obviously, a local anaesthetic applied at the time of a surgical procedure can affect the frequency and intensity of pain in subacute phase, but it is questionable if it can affect chronic post-mastectomy pain syndrome. In our study, the complication rate after a surgical procedure did not differ in patients treated with a continuous infusion of a local anaesthetic through the wound catheter and those who received a standard intravenous opioid analgesia. The experience of other authors who used local anaesthetics is similar. The rates of inflammation or hematomas were not higher after the use of local anaesthetics compared to the placebo or standard analgesia treatment gro ups. $2,5,9,13,15,24-26,28,29,33,34$ On the contrary, local anaesthetics seem to reduce the occurrence of inflammation. ${ }^{35,36,37}$ Like other authors, we also did not notice any toxic side effects of local anaesthetics. In our study, we used $0.25 \%$ levo-bupivacaine, which was reported as one of the safest local anesthetics. ${ }^{38}$

To conclude, our prospective randomized study confirmed that the application of a wound catheter with an elastomeric pump with a local anaesthetic is safe, easy and effective for reducing acute postoperative pain. Continuous infusion of a local anaesthetic into the wound reduces opioid consumption and results in less postoperative sedation and a reduced need for antiemetic drugs. The elastomeric pump is comfortable for both the patients and a nursing stuff. Thus, the patients are more alert, do not feel pain and, consequently, do not need intensive monitoring and nursing care.

\section{References}

1. Merskey H, Bogduk N, editors. Classification of chronic pain: descriptions of chronic pain syndromes and definitions of pain terms. Second edition. Seattle: IASP Press; 1994

2. Talbot $H$, Hutchinson P, Edbrooke DL, Wrench I, Kohlhardt SR. Evaluation of a local anaesthesia regimen following mastectomy. Anaesthesia 2004; 59: 664-7.

3. Katz J, Poleshuck EL, Andrus CH, Hogan LA, Jung BF, Kulick DI, et al. Risk factors for acute pain and its persistence following breast cancer surgery. Pain 2005; 119: 16-25.

4. Almeida TF, Roizenblatt $S$, Tufik S. Afferent pain pathways: a neuroanatomical review. Brain Research 2004; 1000: 40-56. 
5. Schell SR. Patient outcome after axillary lymph node dissection for breast cancer: use of postoperative continuous local anaesthesia infusion. J Surg Res 2006; 134: 124-32

6. Lahajnar CS. [Pain after the surgical treatment in breast cancer patients at the Institute of Oncology Ljubljana.] [Slovenian]. Onkologija 2007; 2: 114-8.

7. Tasmuth T, von Smitten K, Hietaneon P, Kataja M, Kalso E. Pain and other symptoms after different treatment modalities of breast cancer. Ann Oncol 1995; 6: 453-9.

8. Warmuth MA, Bowen G, Prosnitz LR, Chu LO, Broadwater G, Peterson B, et al. Complications of axillary lymph node dissection for carcinoma of the breast: A report based on a patient survey. Cancer 1988; 83: 1362-8.

9. Jacobs VR, Morrison JE Jr. Application of a locally placed anaesthesia catheter for reduction of postoperative pain after mastectomy for breast cancer. Int J Fertil Womens Med 2006; 51: 225-9.

10. Lubenow TR, Ivankovich AD, McCarthy RJ. Management of acute postoperative pain. In: Barash PG, Cullen BF, Stoelting RK, editors. Clinical Anesthesia. 3rd edition. Philadelphia: Lippincott-Rawen; 1997. p. 1305-37.

11. White PF. The role of non-opioid analgesic techniques in the management of pain after ambulatory surgery. Anesth Analg 2002; 94: 577-85.

12. White PF. The changing role of non-opioid analgesic techniques in the management of postoperative pain. Anesth Analg 2005; 101: S5-22.

13. Fassoulaki A, Triga A, Melemeni A, Sarantopoulos C. Multimodal analgesia with gabapentin and local anesthetics prevents acute and chronic pain after breast surgery for cancer. Anesth Analg 2005; 10: 1427-32.

14. Borgeat A, Rawal N, editors. Wound catheter techniques for postoperative analgesia. Cardiff: Darwin Grey Communications; 2008.

15. Rawal N, Axelsson K, Hylander J, Allvin R, Amilon A, Lidegran G, Hallén J. Postoperative patient-controlled local anesthetic administration at home. Anesth Analg 1998; 86: 86-9.

16. Liu SS, Kehlet H. Clinical approach to the patient with postoperative pain. ACS surgery: principles and practice. Hamilton: BC Decker Inc.; 2009.

17. Kay B. A clinical investigation of piritramide in the treatment of postoperative pain. Brit J Anesth 1971; 43: 1167-71.

18. Chernik DA, Gillings D, Laine $H$, Hendler J, Silver JM, Davidson AB, et al. Validity and Reliability of the Observer's Assessment of Alertness/Sedation Scale: study with intravenous midazolam. J Clin Psychpharmacol 1990; 10(4): 244-51.

19. Pilko G, Besic N, Zgajnar J, Hocevar M. Prognostic heterogeneity after the excision of lymph node metastases in patients with cutaneous melanoma. Surg Oncol 2011; 20: 26-34

20. Strojan P. Role of radiotherapy in melanoma management. Radiol Oncol 2010; 44: 1-12.

21. Adamczyk B, Murawa D, Połom K, Spychała A, Nowaczyk P, Murawa P. Preliminary experience in sentinel node and occult lesion localization (SNOLL) technique - One center study. Rep Pract Oncol Radiother 2011; 16: $221-6$

22. Fassoulaki A, Sarantopoulos C, Mlemeni A, Hogan Q. EMLA reduces acute and chronic pain after breast surgery for cancer. Reg Anesth Pain Med 2000; 25: 350-5.

23. Fassoulaki A, Sarantopoulos C, Melemeni A, Hogan Q. Regional block and mexiletine: the effect on pain after cancer breast surgery. Reg Anesth Pain Med 2001; 26: 223-8.

24. Gottschalk A, Burmeister MA, Radtke P, Krieg M, Farokhzad F, Keissl S, et al. Continuous wound infiltration with ropivacaine reduces pain and analgesic requirement after shoulder surgery. Anesth Analg 2003; 97: 1086 -91.

25. Vintar N, Rawal N, Veselko M. Intraarticular patient-controlled regional anesthesia after artroscopically assisted anterior cruciate ligament reconstruction: Ropivcaine/Morphine/Ketrorolac versus Ropivacaine/Morphine. Anesth Analg 2005; 101: 573-8.

26. Beaussier $M$, El'Ayoubi $H$, Schiffer $E$, Rolling $M$, Parc $Y$, Mazoi JX, et al. Continuous preperitoneal infusion of ropivacaine provides effective analgesia and accelerates recovery after colorectal surgery: a randomized, double-blind, placebo-controlled study. Anesthesiology 2007; 107: 461-8.

27. Vintar N, Pozlep G, Rawal N, Godec M, Rakovec S. Incisional self-administration of bupivacaine or ropivacaine provides effective analgesia after inguinal hernia repair. Can J Anaesth 2002; 49: 481-6.
28. Fredman B, Shapiro A, Zohar E, Feldman E, Shorer S, Rawal N, et al. The analgesic efficacy of patient-controlled ropivacaine instillation after Cesarean delivery, Anesth Analg 2000; 91: 1436-40.

29. White PF, Rawal S, Latham P. Use of a continuous local anesthetic infusion for pain management after median sternotomy. Anaesthesiology 2003; 99: 918-23.

30. Barry M, Weber WP, Lee S, Mazzella A, Sclafani LM. Enhancing the clinical pathway for patients undergoing axillary lymph node dissection. Breast 2012; 21: 440-3.

31. Kehlet $\mathrm{H}$, Jensen TS, Woolf $\mathrm{C}$. Persistent postsurgical pain: risk factors and prevention. Lancet 2006; 367: 1618-25.

32. Smith WC, Bourne D, Squair J, Phillips DO, Chambers WA. A retrospective cohort study of post mastectomy pain syndrome. Pain 1999; 83: 91-5.

33. Fisher A, Meller Y. Continuous postoperative regional analgesia by nerve sheath block for amputation surgery - a pilot study. Anesth Analg 1991; 72: $300-3$

34. Obata H, Saito S, Fujina N, Fuse Y, Ishizaki K, Goto F. Epidural block with mepivacaine before surgery reduces long-term post-thoratcotomy pain. Can $J$ Anesth 1999; 46: 1127-32.

35. Sakuragi T, Ishino H, Dan K. Bacatericidal activity of clinically used local anesthetics on Staphylocossus aureus. Reg Anesth 1996; 21: 239-42.

36. Stratford AF, Zoutman DE, Davidson JS. Effect of lidocaine and epinephrine on Staphylococcus aureus in a guinea pig model of surgical wound infection. Plast Reconstr Surg 2002; 110: 1275-9.

37. Parr AM, Zoutman DE, Davidson JS. Antimicrobial activity of lidocaine against bacteria associated with nosocomial wound infection. Ann Plast Surg 1999; 43: 239-45.

38. Mather LE, Copeland SE, Ladd LA. Acute toxicity of local anesthetics: underlying pharmacokinetic and pharmacodynamic concepts. Reg Anesth Pain Med 2005; 30: 553-66. 